\title{
4 \\ Mingling but Not Merging \\ Changes and Continuities in the Identity of Taiwanese in Mainland China
}

Shu Keng and Emmy Ruihua Lin

\section{WHY IS THE IDENTITY OF THE TAIWANESE ON THE MAINLAND AN ISSUE?}

In the past two decades, identity has been the key issue in Taiwanese politics. ${ }^{1}$ Internally, identity issues are central to social cleavages and political competition. Some have used Taiwan's political transition as a way to refute its Chinese origins. Externally, almost everything Taiwan has been doing is related to efforts to defend its national identity. Identity politics has also been at the heart of Taiwan's efforts to determine its foreign policy with China, the United States, and other countries. But "the Taiwanese identity project" may have an Achilles' heel: the identity of the Taiwanese living on the mainland. Since the post-Mao reforms in China, the rapprochement of the Kuomintang (KMT) and the Chinese Communist Party, and the rise of global production/outsourcing networks, the mainland has become the number one destination for Taiwanese foreign investments (and Taiwan is definitely one of the primary sources of China's FDI). Close economic ties triggered several waves of migration from Taiwan to the mainland. According to some estimates, there are between three hundred and four hundred thousand Taiwanese residing in China. ${ }^{2}$

This is a relatively large portion of the small island's population. They and their immediate/direct families amount to about two million people, which is about one-tenth of Taiwan's population. An important question arises as to how these Taiwanese identify themselves. Are they adapting to a Chinese identity or do they still uphold their Taiwanese identity? If the former is the case, they may be a strong and expanding "fifth column" in Taiwanese politics ${ }^{3}$ - but most taishang would be heartbroken to feel that their compatriots viewed them in such a light. Therefore, 
the identity of Taiwanese in mainland China has always been a controversial issue in Taiwan. Some scholars consider these Taiwanese as immigrants and look for signs of assimilation, while others consider them as expatriates and stress their mobility (their travels back and forth between the mainland and Taiwan) and their psychological steadfastness. But the empirical research, after rejecting the earlier "melting-pot" expectations of assimilation (such as Fong Xiaoqian's), has also not fully supported expectations of assimilation that draw on theories of migration (such as Shu Keng's), stressing migrants' difficulties in maintaining ties to their original culture and in withstanding pressures to adopt a new identity. ${ }^{4}$ More than a decade of research has been conducted on this particular subject, but scholars have not reached any agreement on it.

Our own research on this topic started in 2002 and has since been extended via both interview and survey data. In this chapter, we would like to provide a concluding statement on the subject to clarify the current status of Taiwanese identity in China and then to provide some explanation for it. The chapter is divided into five sections. The next one describes the identity of the Taiwanese and raises a puzzle: Why do Taiwanese settle down and blend in, yet refuse to identify themselves as Chinese? The third section tries to explain why Taiwanese maintain their identity. We argue that this has to do with the mobility factor. Being able to travel allows Taiwanese to maintain their strong ties with Taiwan and therefore reduces the impact of living in mainland China. The fourth section deals with the question of why Taiwanese have been reluctant to assume a less "exclusive Taiwanese identity." In this section, we explore the differences and conflicts between Taiwanese and Chinese political and social cultures. In the last part we conclude that the identity of Taiwanese residing on the mainland is typical of identity in the globalizing era. Globalization brought Taiwanese to the mainland, and the resulting changes and continuities illustrate phenomena of transnationalism, cultural conflicts, and the mosaic of national identity.

TAIWANESE ON THE MAINLAND: SETTLING AND ASSIMILATION BUT NO IDENTITY CHANGE

As mentioned earlier, scholars have made different assertions about the identity of Taiwanese residing on the mainland. This could be explained by looking at the political background of the scholars, but it may have more to do with the different dimensions these scholars are focusing upon. In other words, different foci lead to different conclusions. The problem arises as a result of the concept "identity." Identity in this chapter refers to "social identity" or "identity of the related person," especially his or her identification with a social category or group and the degree to which the person considers him- or herself a member of the social category or group. In the context of cross-Strait relations, the identity of Taiwanese people 
could be represented as a choice between Chinese and Taiwanese. But the distinction of "Chinese" versus "Taiwanese" may be confusing in the differing contexts where the concept might apply. Chinese identity could mean "Chinese in a cultural sense" or "Chinese in a nationalistic sense." The survey question commonly used in Taiwan specifies a three-option answer: being Chinese, being Taiwanese, or being both. This could help clarify the issue. On the basis of these types of questions, we can distinguish two types of identities among Taiwanese: an "inclusive Taiwanese identity" (i.e., identifying oneself as "Chinese" or "both") or an "exclusive Taiwanese identity" (i.e., identifying oneself as Taiwanese only).

There are some preliminary qualifications to the issue of identity among Taiwanese residing in mainland China. First, in terms of career planning, only those who would like to settle down and stay on will face the question of identity. Second, regarding social life, only those who would like to reach out and make friends outside their ethnic boundaries confront the question of identity. We can, then, distinguish three aspects of the identity issue: (1) psychological settling, captured by questions about "bringing over the whole family" and "having a long-term plan to stay on"; (2) social assimilation, captured by questions about "who are your close friends" and "who can you and your children marry"; and (3) attitudinal identity: imagined membership in a social group and especially the claiming of an inclusive or exclusive Taiwanese identity.

The study uses data from a collaborative project between the University of Hong Kong and National Chengchi University named "Lives and Attitudes of the Taiwanese in Mainland China," carried out between the summer of 2009 and the winter of 2012. In that survey, the twelve researchers or six research teams spent a total of six weeks interviewing Taiwanese who were settling in both the greater Shanghai area and cities surrounding Dongguan. During the interview, we first asked the interviewees the questions on our semi-structured questionnaire. We then asked further questions regarding previous questions and started more casual talks on related issues. The dialogues were recorded and turned into transcripts for the researcher to keep track of the attitudes and thoughts of the Taiwanese sojourners being interviewed.

Since we have little information about Taiwanese communities in China, the population of our sample, it was difficult for us to design any forms of random sampling on the basis of preexisting information. Instead, we applied the method of snowballing for interviewees and followed the rule of "maximum variation" to diversify our sources of information. As a result, our interviewees include both Taiwanese businessmen and their families and Taiwanese students; both first- and second-generation Taiwanese; employees from both labor-intensive and high-tech manufacturers; employees of Taiwanese firms, joint ventures, foreign firms, and Chinese firms; Taiwanese sojourners of different educational statuses, ranging from primary school to $\mathrm{PhD}$; Taiwanese affiliated with different political factions; 
and Taiwanese of different ethnic origins. In the end, a total of 452 Taiwanese in China were interviewed and their attitudes were documented in a project that proved to be the largest systematic survey of the Taiwanese in China. This allows us to better understand the identity of the Taiwanese in China.

On the basis of the findings summarized in table 3, we can easily see a trend in the identity of the Taiwanese in mainland China: Taiwanese are for the most part settled and can easily blend in, but they refuse to identify themselves as "Chinese."

We find that, first, in terms of physical settling, more than half of the Taiwanese surveyed (52.3 percent) had already brought over their family and settled down in the mainland or had plans to do so. This often is related to long-term career planning, family planning, and a sense of "home" in the locality. As one Taiwanese settled in Shanghai stated, "I have no problem referring to myself as a new Shanghainese." This lays the foundation for the next step, assimilation.

The social assimilation of the Taiwanese can be gauged in two different ways. The first is behavioral and is measured by a question about close friends: even constrained by factors such as arrival time and contacting opportunities, about one-fourth of the Taiwanese (26.3 percent) already considered mainland Chinese as their best friends. The second is attitudinal and is measured by a question about the person they would marry: only about 5 percent ( 5.2 percent) exclude marriage with mainlander Chinese, while most (58.9 percent) feel very agreeable to marrying them. In other words, Taiwanese have no problem at all with crossing the ethnic border to make friendships and establish trust. According to one local Shanghainese, "Compared with the migrants from Jiangsu and Anhui, Taiwanese are nothing special for me, and I would never keep away from them."

Even though Taiwanese plan to settle down and have no problem blending in, they do not want to give up their original identity or adapt to a more lenient and less inclusive identity. As table 3 shows, at least 62 percent of the Taiwanese uphold the "exclusive Taiwan identity." As one young Taiwanese said, "I do come from Shanghai, but if I am mistakenly identified as a Chinese, of course I will correct them immediately. I would never accept the identity of local Chinese." This trend can be better observed by comparing the identity of the Taiwanese in Taiwan to that of the Taiwanese in mainland China, summarized in table 4.

From table 4, we can see that with regard to political positions, especially those related to party identification, there are huge difference between the Taiwanese in Taiwan and those who have moved to China. The percentage of those in the pan-Blue camp (KMT, People First Party [PFP], New Party [CNP], or Minkuotang [MKT]) is almost doubled (26.4 percent vs. 45.1 percent), while the percentage of those in the pan-Green camp (Democratic Progressive Party [DPP], Taiwan Solidarity Union [TSU], Taiwan Independence Party [TAIP], or Taiwan Constitution Association [TCA]) significantly decreases (dropping from 28.6 percent to 15.7 percent). In addition, with respect to a deeper independence-unification position, there are 

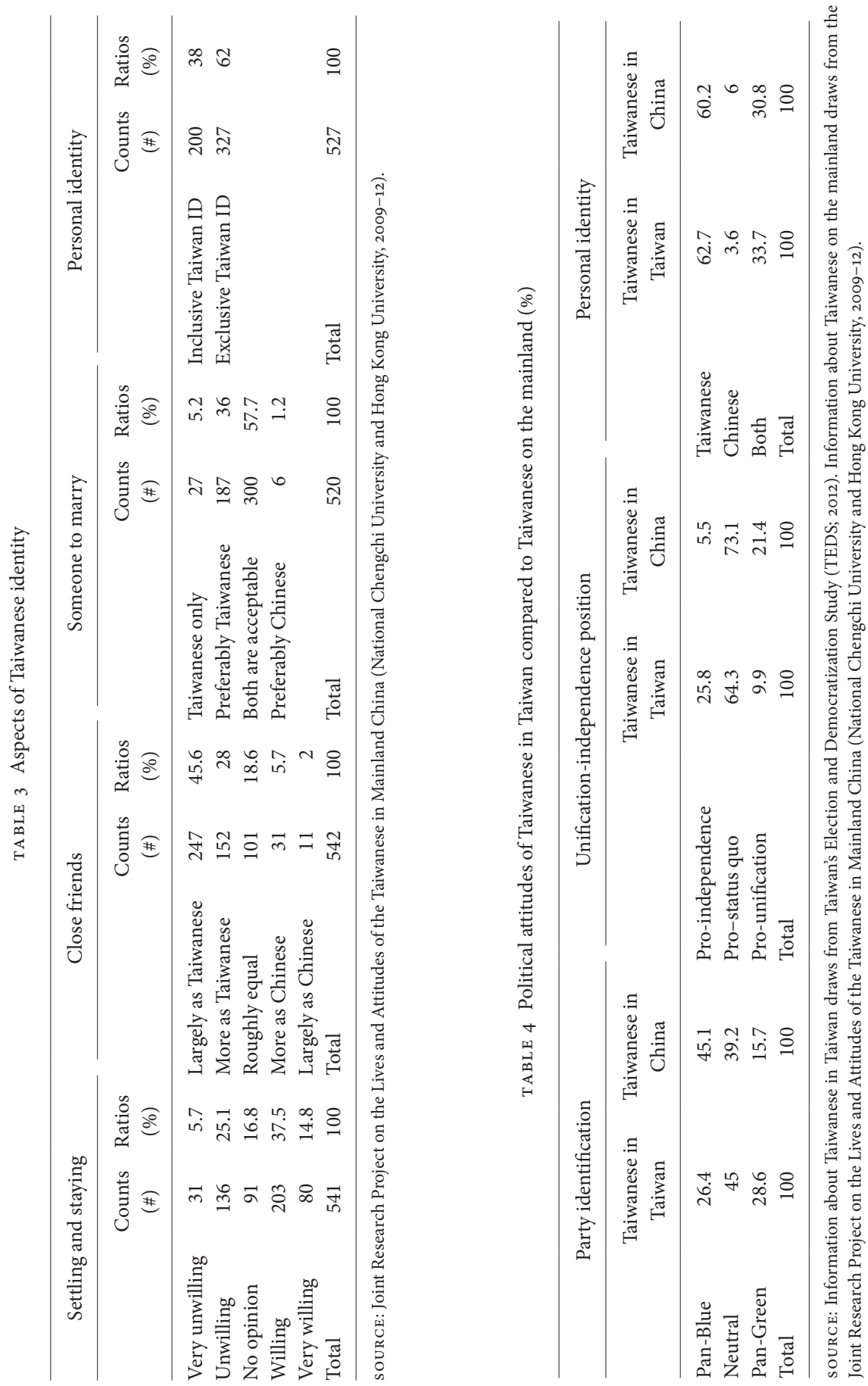
even larger gaps between the Taiwanese in Taiwan and China. The proportion who support independence drops from 25.8 percent to 5.5 percent while the proportion who support pro-unification rises from 9.9 percent to 21.4 percent. If this is the case, then how have attitudes regarding personal identity changed, given that these are often tied to the two above-mentioned positions? As we can see in table 4, there is almost no difference between the Taiwanese in Taiwan and in China: in terms of the "exclusive Taiwan identity," the former proportion is 62.7 percent while the latter is 60.2 percent. In other words, partly because of self-selection and partly because of environmental influences, with respect to party identification and position on the unification/independence issue, the Taiwanese in China are very different from those staying in Taiwan. But the two groups do not significantly differ on the dimension of identity. What explains this puzzling fact? Why are Taiwanese willing to live in China and blend in but at the same time unwilling to change their attitudes toward their identity?

\section{MOBILITY, ASSIMILATION, AND IDENTITY: WHY \\ TAIWANESE HOLD ON TO THEIR IDENTITY}

What is wrong with earlier propositions, which expect a gradual fading away of the Taiwanese identity? And how do Taiwanese uphold their exclusive Taiwanese identity while residing in a new environment? The key here is a tug-of-war between "environmental pressures" and "personal will." In the scenario of conventional immigration, migration is strongly impelled and one-way, and it is difficult for migrants to maintain ties with the sending country/hometown. Therefore, the "environmental pressures" are formidable and most migrants are unable to resist, especially those who are not protected by ethnic communities. In the end, they have to gradually give up their old identity and assume the new identity in a process similar to that envisioned by the "melting pot" model of social assimilation.

This scenario applies to some extent to earlier waves of immigration, such as those of migrants who arrived in New York in the earlier twentieth century. But even historically it has not always applied, and it applies even less in the global era. Often borders can be frequently crossed and recrossed, and, because of innovations in transportation and communication, migrants can easily maintain their ties with their motherland. As a result, we assume that it is easier for them to resist environmental pressures and adhere to their desired identity.

Changing global production networks have brought Taiwanese to an economically and socially less favorable environment in mainland China. Their choice to travel or stay there is to some extent voluntary. Taiwanese are free to come and go. In addition, because of revolutions in transportation and communication technology, cross-border travel and communication are easier and more convenient. Therefore, the pressure to assimilate is not so formidable and irresistible. In 
addition, it is not difficult for Taiwanese to maintain their social and psychological ties with their hometowns. Most Taiwanese that we surveyed had traveled four to six times a year (not for business purposes) back and forth across the Taiwan Strait. As one Taiwanese entrepreneur from Dongguan described, "Many of us still have business in Taiwan. ... At least, we have parents, brothers and sisters, and friends in Taiwan. Of course we have to go and visit them from time to time." And another Taiwanese settled in Shanghai says, "Most of the Taiwanese here subscribe to satellite TV so that they can watch Taiwanese programs, especially Taiwanese news. Of course, some others do not subscribe. But this is because they do not watch TV. I have never heard that any Taiwanese watch Chinese programs all day."

Moreover, in order to promote economic and cultural exchanges internationally, most nation-states manage to facilitate and expedite the process of transferring personnel across national borders. This is also true for travel across the Taiwan Strait, given the unique political situation between China and Taiwan. Both governments accept some replacements for passports and allow some degree of "flexible citizenship" with respect to permanent residence, property ownership, and welfare programs. ${ }^{5}$ This is an arrangement that Tomas Hammar has called denizenship: a status of permanent residency without citizenship, allowing migrants to work and reside permanently in a country but not to have political rights. ${ }^{6}$ Therefore, as one Taiwanese entrepreneur from Kunshan observes, "I have never heard of any Taiwanese giving up their medical insurance program [jianbao], let alone their Taiwanese identity card [shenfenzheng]. No matter how long you stay in China, you would never give up those things."

In other words, all these factors-convenient travel, everyday communications, and the residency arrangements-make it possible for the Taiwanese to easily resist assimilation pressures on the mainland. But mobility does not just "enable" them to hold onto their Taiwanese identity; it also "constrains" them from not doing so. Many of these Taiwanese are uncertain about whether they will settle in China, Taiwan, or perhaps even other places. In this regard, China is just a place to stay. One Taiwanese uses jet lag as a metaphor to describe the mentality: "If you know that you are going to leave in a week, you probably have little incentive to adjust your biological clock." In a sense, the lifestyle of mobility that has developed in an era of globalization has greatly decreased the pressures and incentives to localize, let alone to revise one's personal identity.

From this perspective, the resistance of the Taiwanese to revising their identity has a lot to do with globalization. Therefore this trend does not just apply to the case of Taiwanese in mainland China. It is applicable to most skilled workers and business entrepreneurs traveling across the world. The case of the Taiwanese is unique in the sense that they have traveled to a place with which they share cultural origins. In sum, the ability of the Taiwanese to resist assimilation into local 
Chinese society fully illustrates the significant impact of globalization on the state and its citizens.

\section{CONTACTS, IMAGES, AND IDENTITY: WHY \\ TAIWANESE NEVER GIVE UP THEIR IDENTITY}

Even though Taiwanese can stick to their old identity, they do not necessarily have to. Since most Taiwanese will settle down on the mainland and since few of them have problems blending in there, why do they still refuse to revise their Taiwanese identity to make it more open and inclusive?

Identity refers to a confirmation of one's distinctiveness from others (the contrast of "us" against "them"). The sense of distinctiveness normally comes from the experience of intergroup contacts. If the experiences are negative, so that people create a negative (hostile or derogatory) image of the other, the group boundary will be strengthened and it will be more difficult to relax or break the boundary. This is probably the case with Taiwanese in mainland China. It is very common to find that Taiwanese who hold a positive attitude about China (da zhongguo zhuyi) while living in Taiwan become cynical and negative about China once they when they actually visit or move there. But if so, another thesis (the "contact hypothesis") suggests that frequent and constant contacts may still revise their identity and gradually adjust their relation to Chinese society. And if this is the case, is it be possible that the Taiwanese currently living on the mainland are halfway through a process that will culminate in the replacement of the old Taiwan identity with a new Chinese identity? In other words, is it possible that the assimilation process is just not finished yet and that our conclusion is too hasty?

We believe, on the basis of our fieldwork, that this hypothesis is not true. Intergroup contact does influence migrants and can in the end change one's identity, but it also has its limitations. Migrants do not need to meet everyone; they just deal with those they want to deal with. So identity based on past experiences also directs who one makes contact with and screens some people out. Once people develop a prejudice or stereotype, they avoid some contacts, with the result that they never have experiences that would enable them to revise that prejudice/ stereotype and, ultimately, their identity. As one member of our research team concludes, "Once these Taiwanese believe in the stereotype, they keep minimal contacts with local Chinese. And those superficial contacts cannot challenge the stereotype. More often than not, the stereotypes are confirmed and reconfirmed by their 'selected' contacts. The stereotypes thus reproduce themselves and perpetuate themselves."7 This generalization especially holds for migrants in a higher or superior position: they can choose to meet with whomever they want. And ordinarily Taiwanese on the mainland hold such higher positions. As a result, unless there are some unusual events, it is likely that most Taiwanese will not revise their 
identity no matter how long they stay. Settling down, even permanently, thus has little impact on identity change.

What kinds of experiences, then, play a key role in shaping the image of the Chinese and Chinese society among Taiwanese residing on the mainland? According to our field research, the most influential experiences are those that highlight the differences between Taiwanese and Chinese cultures, which in turn are deeply rooted in economic and political differences between the two countries. Such experiences strengthened respondents' sense of a group boundary between the Chinese and the Taiwanese. In the private sphere, such differences concern how Chinese people show "class" or "civilization" in everyday life (shenghuo shuizhun). If you ask Taiwanese about their impressions of local Chinese, they normally give you examples of spitting, littering, talking loudly, and never observing traffic rules. All these constitute the basis of the belief that Chinese people "have no class" (mei shuizhun) and cause most Taiwanese on the mainland to "feel ashamed if they are misidentified as Chinese." As one young man coming to China for a couple of months commented, "I did not know about this before coming to China. Once I am here, I have a strong feeling: Why should I be a Chinese?" In the public sphere, such differences concern how civilized the Chinese government is perceived to be; respondents describe it as "so backward, so uncivilized, falling behind the government of Taiwan almost a century." In a nutshell, Taiwanese residents' experiences of encountering local Chinese and the local government create a "ladder of class between ethnic groups," and most Taiwanese feel that "we" are superior and "they" are inferior. Therefore, even though they have already physically settled in China and had few problems mixing with Chinese, these Taiwanese simply do not want to "become Chinese." And when they get together with Taiwanese, they often make fun of local Chinese (a-lar-a).

There is variation: for example, Taiwanese settling in metropolitan areas like Shanghai or Beijing tend not to mock local Chinese, whereas those residing in isolated rural factory locales, who encounter local Chinese that are mostly peasants or migrant workers, tend to have negative impressions of local Chinese and to hold an "exclusive Taiwanese identity." Younger Taiwanese are in general more sensitive to the despotism and corruption of local Chinese governments and thus more likely to hold an "exclusive Taiwanese identity." In contrast, those who have had the experience of running a business under the authoritarian government of Taiwan are much less likely to disparage the Chinese government. From these observations we can confirm our field findings that experiences matter: perceived "class" or "civilization" of the Chinese people and government is an important factor that contributes to the variation in negative impressions Taiwanese hold about "China" and explains why they wish to distinguish themselves from the Chinese. We used the data to test the hypotheses drawn from our field research. The results are summarized in table 5. 


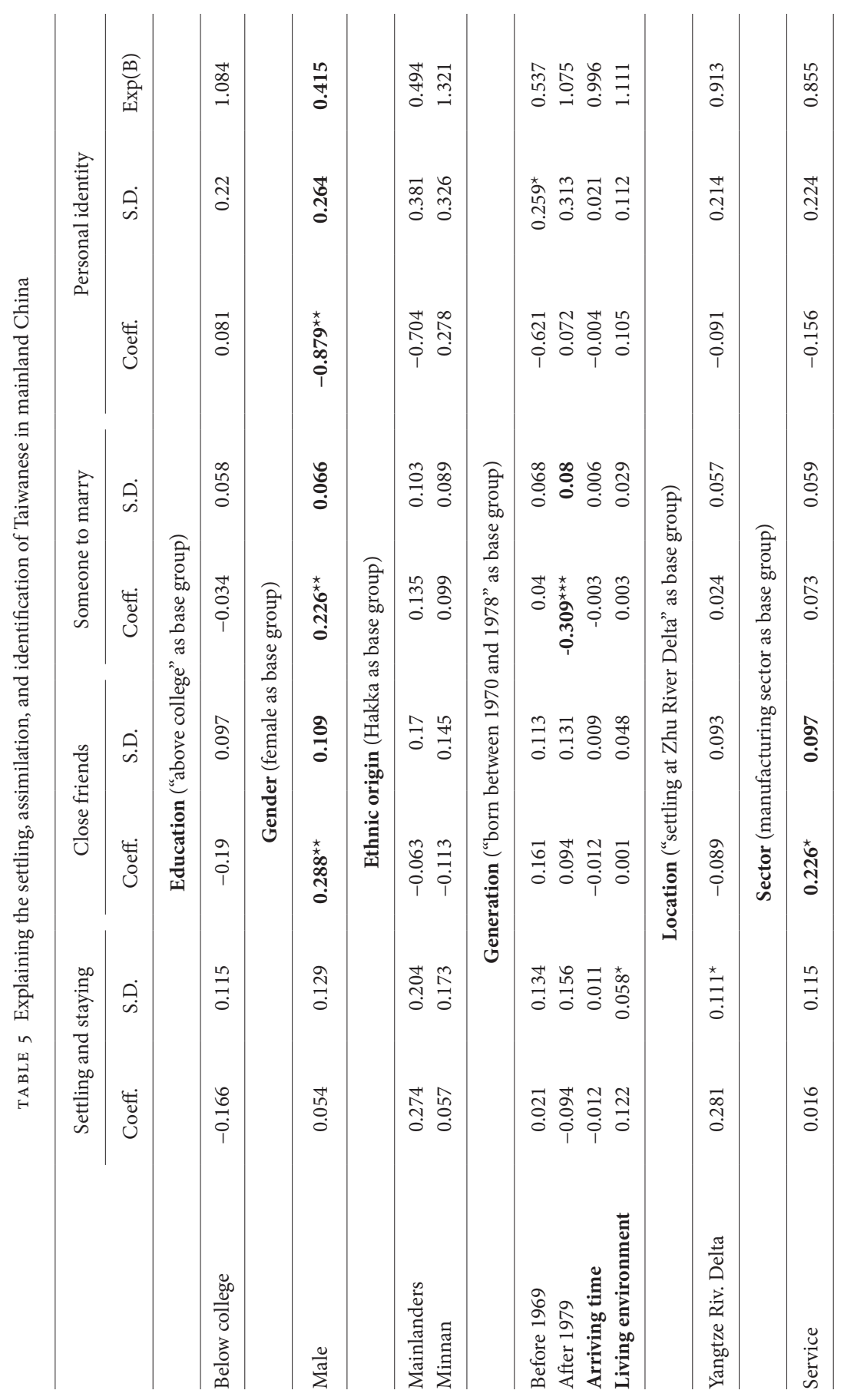




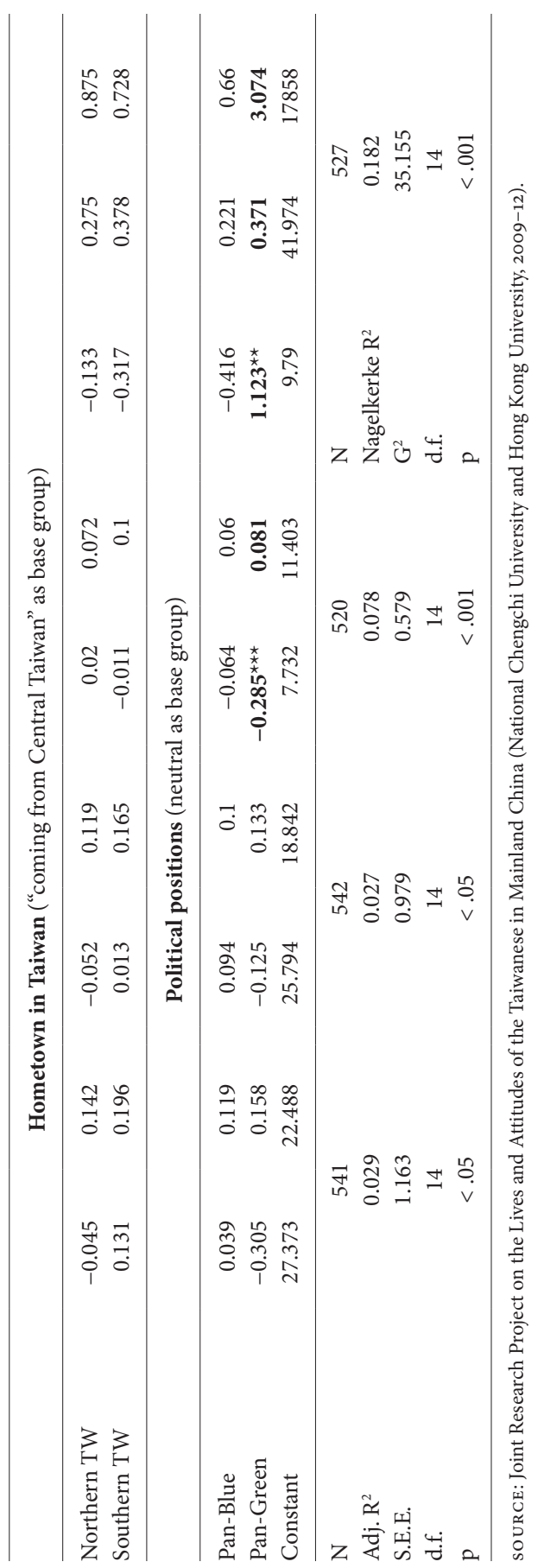


Let us first focus on the background of the interviewees. As we can see in table 5, education does not have a significant effect on identity status-a finding quite different from findings of surveys conducted in Taiwan. Also, gender is significant in shaping the sociability and identity of the mainland-dwelling Taiwanese: men (most businesspeople are male) more easily become close friends with mainlanders and are more conscious and outspoken about their identity. But our research found no evidence of a difference in identity between men and women. As for whether Taiwanese are "natives" (benshengren) or originally migrants to Taiwan from the mainland after the Chinese Civil War (waishengren) does not seem to have any significant effect on their identity. This suggests that the distinction between Taiwanese who came from the mainland and native Taiwanese loses its function as a demarcation line of social cleavage once Taiwanese come to China. Finally, the "generation" factor also fails to demonstrate significant effects on shaping the identity of the Taiwanese, although we found differences between different generations. The general pattern was that younger respondents were more likely to assume an exclusively Taiwanese identity.

In the "contacts and experiences" category, the only category that exerted a significant effect on the identity of the Taiwanese was employment in the service sector, which contributed to cultivation of friendships with local Chinese). None of the factors such as (1) time of arrival, (2) residential area, (2) geographical location, and (4) past life experiences exerted a significant effect. This suggests that earlier expectations about Taiwanese assimilation to Chinese society-based on immigration theories predicting that longer stays in the host country, residence in locations with greater likelihood of intergroup contacts, and more positive experiences of contacts will result in migrants' rapid assimilation-are not supported by empirical evidence.

Finally, one other factor demonstrated significant influence and led to a more open and inclusive position on Taiwanese identity: the person's political position. This may have to do with the above-mentioned factor of the person's impressions of the Chinese government.

\section{IMMIGRATION AND IDENTITY IN THE GLOBAL ERA: WILLINGNESS, RESISTANCE, AND A MOSAIC LANDSCAPE OF NATIONAL IDENTITY}

The purpose of the study is to explore the puzzle of why Taiwanese who have settled on the mainland and could easily blend in persistently refuse to concede on the aspect of identity. In our opinion, a study like this can help enrich and illuminate the theory of migration. Of course, the first controversy we have to face is whether Taiwanese on the mainland can be considered as migrants or whether they are just expatriates. Many, if not most, of the Taiwanese in our study who 
settled down in China would never go back to Taiwan. From this point of view, they are not expatriates. Even though they moved to China without any intention of migration, they finally settled anyway and have had few problems mixing with local Chinese.

But there is another reason that many Taiwanese scholars do not consider these people to be migrants: they still cling to their Taiwanese identity. And that contradicts conventional theories of migrants' assimilation. But in our view, this may have to do with the limitations of the conventional theories. In the common scenarios of those theories, most migrants move in order to migrate and are traveling from worse to better places. In the era of globalization, however, migrants are also traveling around the world and may not plan to permanently reside; also, a significant proportion settle in places with a lower living standard. As a result, many migrants have little incentive to assimilate into the local society, and at the same time they have the ability to keep traveling or to maintain close ties with their motherland. These migrants are thus not migrants in the traditional sense. Some scholars refer to them as "transnational communities."

Our study shows that the Taiwanese in mainland China do not fit the classical definition of "immigrants" and actually exemplify "immigration in the global era." Because Taiwanese share many cultural traits with mainland Chinese, have the ability to blend in with them, yet are reluctant to revise their identity, they perfectly illustrate the new migration process triggered by globalization. Consequently they can give us a better understanding of such concepts as borderlessness, transnationalism, and mosaic-like national identity. They can also help us better understand how cultural gaps and the ability to travel produce changes and continuities in identities in the era of globalization.

Another finding from the research is that the issue of identity for Taiwanese in mainland China is significantly affected by cultural differences across the Taiwan Strait. These have gradually developed over the past six decades of separation, to the point that people on the two sides of the Strait lack many common experiences, thoughts, and feelings. It will take time to narrow this cultural gap. Before China and Taiwan do so, Chinese unification will never occur from the bottom up. These findings help explain why Taiwanese prefer the cross-Strait status quo to either unification or independence. From this perspective, given similar attitudes among the public in Taiwan, it doesn't matter that much whether the KMT's president Ma or the DPP's president Tsai is in power: their China policy would be much the same.

\section{NOTES}

We would like to thank Prof. Richard Weixing Hu, of the University of Hong Kong, for the financial support for data collection and Professor Liping Wang, the Director of the Institute of the Fujian Pilot 
Free Trade Zone at the Party School of Fujian, for administrative support. Also, without the financial support that Shu Keng received from the General Grants for Humanities and Social Sciences Research, Ministry of Education, PRC (Project Code: 14YJAGAToo1), this collaborative research would not have been possible.

1. Alan Wachman, Taiwan: National Identity and Democratization (New York: M. E. Sharpe, 1994); Lowell Dittmer, "Taiwan and the Issue of National Identity, Asian Survey 44, no. 4 (1994): 475-83.

2. Shu Keng, Gunter Schubert, and Emmy Ruihua Lin, eds., Taishang yanjiu [The study of Taiwanese businesspeople in China] (Taipei: Wunan, 2012).

3. Shu Keng and Gunter Schubert, "Agents of Taiwan-China Unification? The Political Roles of Taiwanese Business People in the Process of Cross-Strait Integration," Asian Survey 50, no. 2 (2010): 287-310.

4. Fong Xiaoqian, "Quanqiuhua chongji xia dalu taishang de rengtong wenti" [The identity of mainland China’s Taiwanese businesspeople under globalization], in Shimao zuzhi yu liangan fazhan [The World Trade Organization and cross-Strait development], ed. Xu Guangtai (Taipei: Institute of International Relations, 2003), 489-504; Shu Keng, "Zixunren yihuo Taiwanren? Dashanghai diqu gaokeji taishang de guojia renting" [Merely professionals or still Taiwanese? The national identity of the Taiwanese in the high-tech sector in Greater Shanghai], paper presented at the Second Annual Conference on Politics and Information (Yilan: Foguang University, 2002).

5. Aihwa Ong, Flexible Citizenship: The Cultural Logics of Transnationality (Durham, NC: Duke University Press, 1999).

6. Tomas Hammar, "State, Nation, and Dual Citizenship," in Immigration and the Politics of Citizenship in Europe and North America, ed. W. R. Brubaker (Lanham, MD: University Press of America, 1989), cited in Yen-fen Tseng and Jieh-min Wu, "Reconfiguring Citizenship and Nationality: Dual Citizenship of Taiwanese Migrants in China," Citizenship Studies 15, no. 2 (2011): 265-82.

7. Jiang Yiqing, "Qunji jiechu dui denglu taiwanren dangdihua zhi yingxiang: Yi Dongguan ji Shanghai weili" [The impacts of inter-group contacts on the assimilation of the Taiwanese in mainland China: The study of Dongguan and Shanghai] (MA thesis, Graduate Institute of East Asian Studies, National Chengchi University, 2006). 